\title{
Soluble CD163 as a surrogate marker of fibrosis regression in chronic HCV patients receiving direct antiviral agents
}

\author{
Amira Isaac*, Ahmed Aly Mo'nes, Wesam Essam Aly, Hesham Hamdy El-Kilany
}

Internal Medicine Department, Hepatology and Gastroenterology unit, Faculty of medicine, Ain Shams University, Cairo, Egypt

*Corresponding author: Amira Isaac Samaan

E-mail:dr.amira@med.asu.edu.eg

Tel:01222216927

Running title: Chronic hepatitis C and soluble CD163

\section{Contributors:}

\section{Dr. Amira Isaac Samaan, MD}

Lecturer of Internal Medicine, Faculty of Medicine, Ain Shams University, Cairo, Egypt

\section{Dr. Ahmed Aly Mo'nes, MD}

Professor of Internal Medicine, Faculty of Medicine, Ain Shams University, Cairo, Egypt

\section{Dr. Wesam Essam Aly Wassfy}

Assistant Lecturer of Internal Medicine, Faculty of Medicine, Ain Shams University, Cairo, Egypt

\section{Dr. Hesham Hamdy El-Kilany, MD}

Assistant Professor of Internal Medicine, Faculty of Medicine, Ain Shams University, Cairo, Egypt

\section{ABSTRACT}

Background: Over 80 million people are infected globally with chronic HCV. It promotes inflammation and, hence. hepato-carcinogenesis. As a result, resolving HCV infection should result in decreased incidence of hepatocellular carcinoma. Oral DAAs introduction has changed overall prognosis of HCV. SVR has been linked to improved liver function as well as a reduction in clinical consequences and all-cause mortality. Monocytes and macrophages generate CD163, a hemoglobin scavenger receptor. In a variety of hepatic and viral disorders, soluble CD163 is a well-established marker of portal hypertension and disease severity. In addition, in chronic HCV infection there have been strong connections between macrophage activation, histological inflammation and fibrosis. Our goal is to assess the role of soluble CD163 as a surrogate marker for detection of fibrosis regression in HCV patients treated with direct antiviral agents. 
Results: Forty chronic HCV patients and ten healthy subjects were included in this study. Serum sCD163 was tested before and 12 weeks after treatment by DAAs. Mean values of sCD163 were statistically significantly higher in chronic HCV case group in comparison to control group, and they showed statistically significant decline after achievement of SVR12 weeks with $\mathrm{p}$ value of $<0.001$. On calculating different fibrosis scoring scores (APRI and FIB-4) differences between pretreatment and SVR12 results showed no statistical significance. While on applying fibroscan a significant down-staging was detected in fibrosis scores 12 weeks after achieving SVR. our study demonstrated that the best cut-off values of baseline sCD163 in detection of liver cirrhosis was $>6.2 \mathrm{ng} / \mathrm{ml}$ with $87.50 \%$ sensitivity, 95.83\% specificity, with overall accuracy of $97.2 \%$.

Conclusion: sCD163 serum level declines with successful DAA therapy and is associated with regression in staging of fibrosis supporting its promising role in monitoring treatment response rather than other methods of fibrosis measurement.

\section{Keywords: HCV, sCD163, APRI, FIB-4, Fibroscan.}

\section{Background}

Hepatitis $\mathrm{C}$ virus (HCV) infection has variable long-term consequences, including chronic hepatitis, progressive fibrosis, cirrhosis, hepatocellular carcinoma (HCC) and extra hepatic manifestations [1].

The main goal of $\mathrm{HCV}$ eradication is to reduce hepatic and extra-hepatic consequences while also improving overall survival [2]. Advances in HCV treatment have resulted in cure rates of more than $90 \%$, as defined by sustained virologic response (SVR), which is undetectable HCV RNA 12 weeks (SVR12) or 24 weeks (SVR24) following end of treatment (EOT). Long-term studies have demonstrated that in more than 99 percent of cases SVR correlates to complete cure of HCV infection [3].

Given progress in HCV treatment using direct acting antivirals (DAAs), it is necessary to simplify diagnostic confirmation and treatment surveillance methods to allow wide access to these new medications. This necessitates the need for follow up by markers that implicates successful response, one of which is the hemoglobin-haptoglobin scavenger receptor CD163, which is only found on the surface of monocytes and macrophages [4].

Kupffer cells, the liver's resident macrophages, release reactive oxygen species, cytokines, and interleukins in response to various stimuli, which influence hepatocellular development but may also maintain inflammation and cause hepatic cell death. Soluble CD163 (sCD163) has been identified as a marker for macrophages activation [5].

Over expression of sCD163 may be a sign of developing inflammation. Patients with fulminant hepatic failure had considerably higher sCD163 levels than those with hepatitis; it has also been reported as mortality predictor in patients with acute liver failure, cirrhosis and HCC. As a result, the clinical significance of CD163 expression in liver tissue and peripheral blood is of peculiar concern [6]. 
So, the aim of this study is to validate the role of soluble CD163 in prediction of fibrosis regression in chronic $\mathrm{HCV}$ patients treated with direct acing antiviral agents.

\section{Methods:}

During the period of January to August 2019, 40 Egyptian chronic HCV infected patients $>18$ years old who were eligible for antiviral treatment with DAAs and agreed to regular follow up were recruited from the National Committee for Control of Viral Hepatitis (NCCVH) regional center in Ain Shams university hospital, and 10 healthy volunteers not infected with HCV served as a control group, participated in the study after taking informed consents and obtaining approval of Ain Shams University ethics committee.

The naive case group comprises forty chronic $\mathrm{HCV}$ patients who had positive $\mathrm{HCVAb}$ for at least six months, and detectable quantitative HCV RNA. They were treated with individually tailored DAAs regimen of Sofosbuvir 400mg + Daclatasvir 60mg \pm Ribavirin $1000-1200 \mathrm{mg}$ as per the Egyptian NCCVH protocol for three months during the study course [7].

Application of exclusion criteria was taking in consideration co-infection with HBV or HIV, HCC or extra-hepatic malignancies except after two years of disease-free interval, obesity, Pregnancy or inability to use contraception, previous or current heavy alcohol consumption, or previous DAAs treatment experience.

\section{I- Pre-enrollment assessment and work up:}

All patients underwent the following:

- Full history taking including history of chronic liver disease, symptoms of hepatic decompensation

- Full clinical examination, general and local, for the stigmata of chronic liver disease.

- Initial laboratory assessment including:

- Liver profile: alanine transaminase (ALT), aspartate transaminase (AST), serum albumin, total and direct bilirubin, INR, alpha-fetoprotein (AFP).

○ Complete blood count with differential (CBC).

○ HCV quantitative RNA via Polymerase Chain Reaction (PCR).

○ HBsAg -HCVAb - HIVAb.

○ Serum creatinine level.

- Fasting blood sugar (FBS) and HbA1c for diabetic patients.

○ Soluble CD 163 measured by Macro 163 sandwich ELISA according to manufacturer instructions. 
- Abdominal Ultrasound: Performed with the patient resting in a supine position after an overnight fast (7 hours) with an emphasis on liver size and echogenicity, splenic bi-polar diameter and portal vein diameter.

\section{- Calculation of Child-Pugh score}

- Calculating APRI score: The AST to Platelet Ratio Index (AST level (IU/L)/AST upper normal level (IU/L)) /platelet count $\left(10^{9} / \mathrm{L}\right)$ x 100 . The lower the APRI score (less than 0.5 ), the greater the negative predictive value (NPV) (and capacity to rule out cirrhosis) and the higher the value (greater than 1.5) the greater the positive predictive value (PPV) (and ability to rule in cirrhosis); midrange values are less useful [8].

- Calculating FIB-4 score: The Fibrosis-4 index is calculated using the formula: FIB-4 = Age (years) $\times$ AST (IU/L)/ [PLT $\left(10^{9} / \mathrm{L}\right) \times$ ALT1/2 (IU/L)]. FIB-4 has a NPV of $90 \%$ of advanced fibrosis at a cutoff value of $<1.45$. In contrast, a FIB-4 $>3.25$ would have a $97 \%$ specificity and a PPV of $65 \%$ for advanced fibrosis [9].

- Ultrasound elastography: It employs a modified ultrasound probe to measure the velocity of a shear wave induced by a vibratory source and is marketed as FibroScan ${ }^{\circledR}$. Ultrasound measurements of liver stiffness correlate with fibrosis stage. The kilopascal $(\mathrm{kPa})$ scale is used to measure the results, which range from 2 to 75 . A FibroScan ®'s normal range is between 2 and $7 \mathrm{kPa}$. The normal result is $5.3 \mathrm{kPa}$ on average. There are four phases of scarring: $\bullet$ F0 indicates that there is no scarring; F1 indicates mild fibrosis; F2 indicates moderate fibrosis; F3 indicates severe fibrosis; and F4 indicates cirrhosis or advanced fibrosis.

II- Follow up 12 weeks after end of treatment:

All patients were tested for

- Soluble CD 163 level.

- HCV RNA to evaluate SVR12.

- Calculation of APRI score.

- Calculation of FIB-4 score.

- Ultrasound elastography.

\section{Results}

This study included forty chronic HCV patients eligible for treatment with DAAs (Naïve case group), they were 24 males and 16 females with mean age $(41.800 \pm 10.146)$ and ten heathy age and sex matched subjects (control group), they were 6 males and 4 females with mean age $(36.600 \pm 12.020)$

As regard the biochemical parameters, the mean values of all components of complete blood picture (CBC) and serum albumin level were statistically significantly lower among naïve case group. While the mean values of total bilirubin, direct bilirubin and INR were statistically significantly higher among naïve case group compared to control group (Table $1)$. 
Mean values of sCD163 were found to be statistically significantly higher in Naïve case group in comparison to control group (Table 2).

Regarding hepatic texture by ultrasound and fibroscan, sCD163 was statistically significantly higher in cirrhotic patients by ultrasound or $\mathrm{F} 4$ by fibroscan than in non-cirrhotic patients (Table 3).

All naive chronic HCV patients got new DAAs for 12 weeks and were evaluated 12 weeks later, with undetectable serum HCV RNA concentrations in all cases (SVR 12). The statistical variations in $\mathrm{CBC}$ and liver function tests between pretreatment and 12 weeks after EOT are shown in (Table 4).

On calculating different fibrosis scoring scores (APRI and FIB-4) variations between pretreatment and 12 weeks after EOT shows no statistical significance. While on applying fibroscan there was a significant down-staging in fibrosis score 12 weeks after achieving SVR (Table 5)

A statistically significant decline of sCD163 was seen after achievement of SVR 12 weeks with $\mathrm{p}$ value of $<0.001$ (Table 6 )

A statistically significant positive correlation was noted between sCD163 level before treatment with total and direct bilirubin, INR, HCV-RNA, AFP, APRI, FIB-4, Child-Pugh score, splenic size, PV diameter and fibroscan, and a statistically significant negative correlation with complete blood picture, albumin and liver size (Table 7)

Finally, our study demonstrated the best cut-off value of baseline sCD163 in detection of liver cirrhosis as $>6.2 \mathrm{ng} / \mathrm{ml}$ with $87.50 \%$ sensitivity, $95.83 \%$ specificity, $93.3 \%$ PPV and $92.0 \% \mathrm{NPV}$

Table (1): Comparison between cases before treatment and control regarding biochemical parameters

\begin{tabular}{|c|c|c|c|c|c|}
\hline & & \multicolumn{2}{|c|}{ Groups } & \multicolumn{2}{|c|}{ T-Test } \\
\hline & & Naïve Patients & Control & $\mathbf{T}$ & P-value \\
\hline \multirow{2}{*}{$\begin{array}{c}\text { Total leucocyte count } \\
\left(10^{3} / \mathrm{ul}\right)\end{array}$} & Range & 2.9-9.2 & 6-8 & \multirow{2}{*}{-2.093} & \multirow{2}{*}{$0.042 *$} \\
\hline & Mean \pm SD & $5.730 \pm 1.718$ & $6.900 \pm 0.738$ & & \\
\hline \multirow{2}{*}{$\begin{array}{l}\text { Hemoglobin } \\
\text { (g/dl) }\end{array}$} & Range & $8.9-14.8$ & $11-15$ & \multirow{2}{*}{-2.852} & \multirow{2}{*}{$0.006^{*}$} \\
\hline & Mean \pm SD & $11.398 \pm 1.695$ & $13.040 \pm 1.306$ & & \\
\hline \multirow{2}{*}{$\begin{array}{l}\text { Platelet count } \\
\qquad\left(10^{3} / \mathrm{ul}\right)\end{array}$} & Range & $70-550$ & $340-540$ & \multirow{2}{*}{-3.056} & \multirow{2}{*}{$0.004 *$} \\
\hline & Mean \pm SD & $275.175 \pm 166.176$ & $440.500 \pm 72.394$ & & \\
\hline \multirow{2}{*}{$\begin{array}{l}\text { AST } \\
\text { (IU/L) }\end{array}$} & Range & $12-28$ & $12-22$ & \multirow{2}{*}{0.164} & \multirow{2}{*}{0.870} \\
\hline & Mean \pm SD & $17.225 \pm 4.035$ & $17.000 \pm 3.091$ & & \\
\hline
\end{tabular}




\begin{tabular}{|c|c|c|c|c|c|}
\hline \multirow{2}{*}{$\begin{array}{c}\text { ALT } \\
(\mathrm{IU} / \mathrm{L})\end{array}$} & Range & $10-24$ & $12-23$ & \multirow{2}{*}{-0.665} & \multirow{2}{*}{0.509} \\
\hline & Mean \pm SD & $15.975 \pm 3.932$ & $16.900 \pm 3.957$ & & \\
\hline \multirow{2}{*}{$\begin{array}{l}\text { Total Bilirubin } \\
\text { (mg/dl) }\end{array}$} & Range & $0.4-2.8$ & $0.5-1.2$ & \multirow{2}{*}{2.703} & \multirow{2}{*}{$0.009 *$} \\
\hline & Mean \pm SD & $1.340 \pm 0.557$ & $0.850 \pm 0.237$ & & \\
\hline \multirow{2}{*}{$\begin{array}{l}\text { Direct Bilirubin } \\
(\mathrm{mg} / \mathrm{dl})\end{array}$} & Range & 0.2-1.9 & 0.3-0.7 & \multirow{2}{*}{2.415} & \multirow{2}{*}{$0.020 *$} \\
\hline & Mean \pm SD & $0.713 \pm 0.349$ & $0.440 \pm 0.117$ & & \\
\hline \multirow{2}{*}{$\begin{array}{l}\text { Albumin } \\
\text { (g/dl) }\end{array}$} & Range & $0.4-4.3$ & $3.6-4.2$ & \multirow{2}{*}{-2.567} & \multirow{2}{*}{$0.013^{*}$} \\
\hline & Mean \pm SD & $3.335 \pm 0.660$ & $3.880 \pm 0.187$ & & \\
\hline \multirow{2}{*}{ INR } & Range & $1-1.7$ & $1-1.2$ & \multirow{2}{*}{2.424} & \multirow{2}{*}{$0.019 *$} \\
\hline & Mean \pm SD & $1.216 \pm 0.213$ & $1.050 \pm 0.071$ & & \\
\hline \multirow{2}{*}{$\begin{array}{l}\text { Creatinine } \\
\text { (mg/dl) }\end{array}$} & Range & $0.6-1.1$ & $0.6-1.1$ & \multirow{2}{*}{-0.370} & \multirow{2}{*}{0.713} \\
\hline & Mean \pm SD & $0.853 \pm 0.130$ & $0.870 \pm 0.149$ & & \\
\hline
\end{tabular}

Table (2): Comparison between patients before treatment and control regarding $\mathrm{sCD} 163$ (ng/mL).

\begin{tabular}{|c|c|c|c|c|c|}
\hline \multirow{2}{*}{\multicolumn{2}{|c|}{ SCD 163}} & \multicolumn{2}{|c|}{ Groups } & \multicolumn{2}{|c|}{ T-Test } \\
\hline & & Patients & Control & $\mathbf{t}$ & P-value \\
\hline \multirow{2}{*}{$\begin{array}{c}\text { Before } \\
\text { treatment }\end{array}$} & Range & $2.5-9.2$ & $1.3-2.3$ & \multirow{2}{*}{6.606} & \multirow{2}{*}{$<0.001^{*}$} \\
\hline & Mean $\pm S D$ & $5.748 \pm 1.854$ & $1.830 \pm 0.333$ & & \\
\hline
\end{tabular}

Table (3): Comparison between hepatic texture, fibroscan and child score with sCD163 level in patients before treatment.

\begin{tabular}{|c|c|c|c|c|c|}
\hline & & \multicolumn{2}{|c|}{$\begin{array}{c}\text { SCD } 163 \\
\text { before treatment }\end{array}$} & \multicolumn{2}{|c|}{$\begin{array}{l}\text { T-Test or } \\
\text { ANOVA }\end{array}$} \\
\hline & & $\mathbf{N}$ & Mean \pm SD & $T$ or $F$ & $\begin{array}{c}\text { P- } \\
\text { Value }\end{array}$ \\
\hline \multirow{2}{*}{ Gender } & Male & 24 & $5.571 \pm 1.915$ & \multirow{2}{*}{-0.734} & \multirow{2}{*}{0.468} \\
\hline & Female & 16 & $6.013 \pm 1.786$ & & \\
\hline \multirow{2}{*}{$\begin{array}{l}\text { Hepatic texture } \\
\text { before treatment }\end{array}$} & Non-Cirrhotic & 23 & $4.535 \pm 1.001$ & \multirow{2}{*}{-7.451} & \multirow{2}{*}{$<0.001^{*}$} \\
\hline & Cirrhotic & 17 & $7.388 \pm 1.424$ & & \\
\hline \multirow{4}{*}{$\begin{array}{c}\text { Fibroscan } \\
\text { before treatment }\end{array}$} & F1 & 10 & $4.360 \pm 1.035$ & \multirow{4}{*}{28.273} & \multirow{4}{*}{$<0.001^{*}$} \\
\hline & F2 & 12 & $4.783 \pm 0.945$ & & \\
\hline & F3 & 2 & $3.650 \pm 0.495$ & & \\
\hline & F4 & 16 & $7.600 \pm 1.162$ & & \\
\hline
\end{tabular}




\begin{tabular}{|c|c|c|c|c|c|}
\hline \multirow{2}{*}{$\begin{array}{c}\text { Fibroscan } \\
\text { before treatment }\end{array}$} & $F 1 \& 2 \& 3$ & 24 & $4.513 \pm 0.985$ & \multirow{2}{*}{-9.041} & \multirow{2}{*}{$<0.001^{*}$} \\
\hline & F4 & 16 & $7.600 \pm 1.162$ & & \\
\hline \multirow{3}{*}{$\begin{array}{c}\text { Child score } \\
\text { before treatment }\end{array}$} & Child A & 31 & $5.542 \pm 1.753$ & \multirow{3}{*}{1.253} & \multirow{3}{*}{0.297} \\
\hline & Child B & 8 & $6.263 \pm 2.182$ & & \\
\hline & Child C & 1 & $8.000 \pm 0.000$ & & \\
\hline
\end{tabular}

Table (4): Comparison between different biochemical parameters of patients before and 12 weeks after treatment

\begin{tabular}{|c|c|c|c|c|c|c|c|}
\hline & & \multicolumn{2}{|c|}{ Time } & \multicolumn{2}{|c|}{ Differences } & \multicolumn{2}{|c|}{ Paired Test } \\
\hline & & $\begin{array}{l}\text { Before } \\
\text { treatment }\end{array}$ & $\begin{array}{c}12 \text { Weeks } \\
\text { After treatment }\end{array}$ & Mean & SD & $\mathbf{T}$ & P-value \\
\hline \multirow[b]{2}{*}{$\begin{array}{l}\text { Total leucocyte count } \\
\qquad\left(10^{3} / \text { ul }\right)\end{array}$} & Range & $2.9-9.2$ & $3-7.2$ & \multirow[b]{2}{*}{0.365} & \multirow[b]{2}{*}{0.834} & \multirow[b]{2}{*}{2.767} & \multirow[b]{2}{*}{$0.009 *$} \\
\hline & $\begin{array}{c}\text { Mean } \\
\pm S D\end{array}$ & $5.730 \pm 1.718$ & $5.365 \pm 1.267$ & & & & \\
\hline \multirow[b]{2}{*}{$\begin{array}{l}\text { Hemoglobin } \\
\text { (g/dl) }\end{array}$} & Range & $8.9-14.8$ & $9-14.2$ & \multirow[b]{2}{*}{0.238} & \multirow[b]{2}{*}{0.854} & \multirow[b]{2}{*}{1.759} & \multirow[b]{2}{*}{0.086} \\
\hline & $\begin{array}{c}\text { Mean } \\
\pm S D\end{array}$ & $11.398 \pm 1.695$ & $11.160 \pm 1.512$ & & & & \\
\hline \multirow[b]{2}{*}{$\begin{array}{l}\text { Platelet count } \\
\left(10^{3} / \mathrm{ul}\right)\end{array}$} & Range & $70-550$ & $69-513$ & \multirow[b]{2}{*}{-7.600} & \multirow[b]{2}{*}{41.504} & \multirow[b]{2}{*}{-1.158} & \multirow[b]{2}{*}{0.254} \\
\hline & $\begin{array}{c}\text { Mean } \\
\pm S D\end{array}$ & $\begin{array}{c}275.175 \pm \\
166.176\end{array}$ & $282.775 \pm 167.821$ & & & & \\
\hline \multirow[b]{2}{*}{$\begin{array}{c}\text { AST } \\
\text { (IU/L) }\end{array}$} & Range & $12-28$ & $12-24$ & \multirow[b]{2}{*}{-0.125} & \multirow[b]{2}{*}{2.729} & \multirow[b]{2}{*}{-0.290} & \multirow[b]{2}{*}{0.774} \\
\hline & $\begin{array}{c}\text { Mean } \\
\pm S D\end{array}$ & $17.225 \pm 4.035$ & $17.350 \pm 3.490$ & & & & \\
\hline \multirow[b]{2}{*}{$\begin{array}{c}\text { ALT } \\
\text { (IU/L) }\end{array}$} & Range & $10-24$ & $10-23$ & \multirow[b]{2}{*}{-0.350} & \multirow[b]{2}{*}{2.348} & \multirow[b]{2}{*}{-0.943} & \multirow[b]{2}{*}{0.352} \\
\hline & $\begin{array}{l}\text { Mean } \\
\pm S D\end{array}$ & $15.975 \pm 3.932$ & $16.325 \pm 3.892$ & & & & \\
\hline \multirow[b]{2}{*}{$\begin{array}{l}\text { Total Bilirubin } \\
\text { (mg/dl) }\end{array}$} & Range & $0.4-2.8$ & $0.5-2.7$ & \multirow[b]{2}{*}{-0.018} & \multirow[b]{2}{*}{0.265} & \multirow[b]{2}{*}{-0.418} & \multirow[b]{2}{*}{0.678} \\
\hline & $\begin{array}{l}\text { Mean } \\
\pm S D\end{array}$ & $1.340 \pm 0.557$ & $1.358 \pm 0.489$ & & & & \\
\hline \multirow{2}{*}{$\begin{array}{l}\text { Direct Bilirubin } \\
(\mathrm{mg} / \mathrm{dl})\end{array}$} & Range & $0.2-1.9$ & $0.3-1.8$ & \multirow[b]{2}{*}{-0.048} & & & \\
\hline & $\begin{array}{c}\text { Mean } \\
\pm \text { SD }\end{array}$ & $0.713 \pm 0.349$ & $0.760 \pm 0.302$ & & 0.184 & -1.633 & 0.110 \\
\hline & Range & $0.4-4.3$ & $2.4-4.2$ & & & & \\
\hline $\begin{array}{l}\text { Albumin } \\
\text { (g/dl) }\end{array}$ & $\begin{array}{c}\text { Mean } \\
\pm S D\end{array}$ & $3.335 \pm 0.660$ & $3.445 \pm 0.449$ & -0.110 & 0.494 & -1.408 & 0.167 \\
\hline & Range & $1-1.7$ & $1-1.7$ & & & & \\
\hline INR & $\begin{array}{c}\text { Mean } \\
\pm S D\end{array}$ & $1.216 \pm 0.213$ & $1.175 \pm 0.198$ & 0.041 & 0.130 & 2.014 & 0.051 \\
\hline
\end{tabular}


Creatinine

(mg/dl)

\begin{tabular}{|c|c|c|}
\hline Range & $0.6-1.1$ & $0.7-1.1$ \\
\hline $\begin{array}{c}\text { Mean } \\
\pm S D\end{array}$ & $0.853 \pm 0.130$ & $0.891 \pm 0.100$ \\
\hline
\end{tabular}

$-0.039$

Table (5): Comparison between patients before and 12 weeks after treatment regarding APRI score, FIB-4 score and fibroscan.

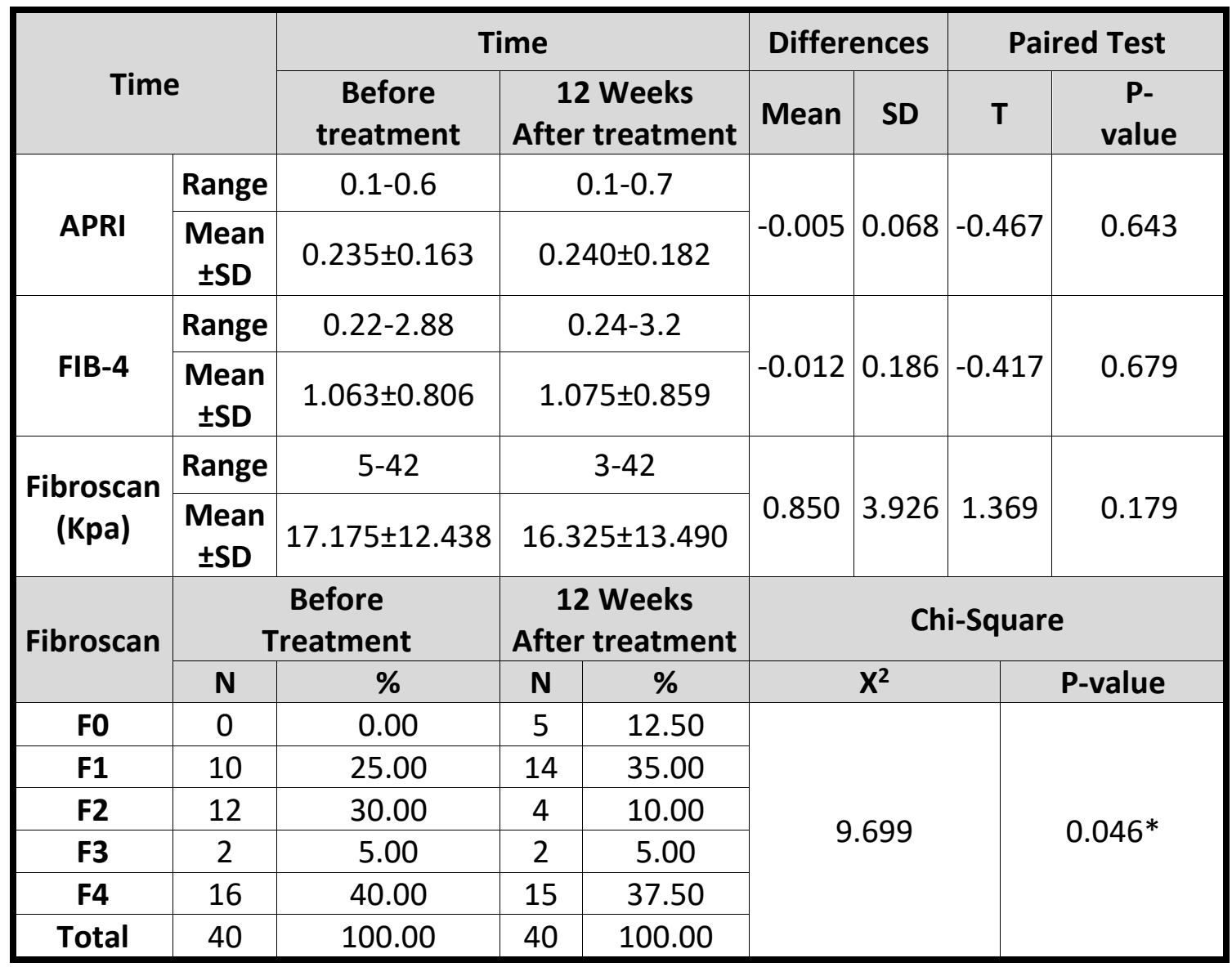

Table (6): Comparison between patients before and 12 weeks after treatment regarding $\mathrm{SCD} 163$

\begin{tabular}{|l|c|ccc|c|c|c|}
\hline \multirow{2}{*}{ Time } & \multicolumn{4}{|c|}{ SCD 163(ng/ml) } & \multicolumn{2}{c|}{ Differences } & \multirow{2}{*}{ P-value } \\
\cline { 2 - 7 } & Range & Mean & \pm & SD & Mean & SD & \\
\hline \multirow{2}{*}{ Before treatment } & $2.5-9.2$ & 5.748 & \pm & 1.854 & 1.725 & 1.478 & $<0.001 *$ \\
\hline
\end{tabular}


Table (7): Correlation between sCD163 and all other parameters in patients before treatment

\begin{tabular}{|c|c|c|}
\hline \multicolumn{3}{|c|}{ Correlations } \\
\hline & \multicolumn{2}{|c|}{ SCD 163 Before treatment } \\
\hline & $\mathbf{R}$ & P-value \\
\hline Age & 0.246 & 0.126 \\
\hline TLC Before treatment & -0.723 & $<0.001^{*}$ \\
\hline HB Before treatment & -0.541 & $<0.001 *$ \\
\hline PLT Before treatment & -0.685 & $<0.001^{*}$ \\
\hline AST Before treatment & -0.163 & 0.315 \\
\hline ALT Before treatment & -0.053 & 0.744 \\
\hline T.BIL Before treatment & 0.569 & $<0.001 *$ \\
\hline D.BIL Before treatment & 0.566 & $<0.001 *$ \\
\hline ALB. Before treatment & -0.434 & $0.005^{*}$ \\
\hline INR Before treatment & 0.767 & $<0.001 *$ \\
\hline PCR-HCV Before treatment & 0.455 & $0.003 *$ \\
\hline AFP Before treatment & 0.723 & $<0.001^{*}$ \\
\hline APRI Before treatment & 0.754 & $<0.001 *$ \\
\hline FIB-4 Before treatment & 0.748 & $<0.001^{*}$ \\
\hline Child pugh score Before treatment & 0.356 & $0.024 *$ \\
\hline Liver size $(\mathrm{cm})$ Before treatment & -0.635 & $<0.001 *$ \\
\hline Splenic size $(\mathrm{cm})$ Before treatment & 0.726 & $<0.001^{*}$ \\
\hline PV Diameter $(\mathrm{mm})$ Before treatment & 0.758 & $<0.001 *$ \\
\hline Fibroscan (Kpa) Before treatment & 0.815 & $<0.001^{*}$ \\
\hline
\end{tabular}

Table (8): ROC curve of best cut off value of baseline sCD163 in differentiation between non-cirrhotic $(\mathrm{F} 1+\mathrm{F} 2+\mathrm{F} 3)$ and cirrhotic $(\mathrm{F} 4)$ patients

ROC curve between F1\&2\& 3 and F4

\begin{tabular}{l|c|c|c|c|c|} 
Cutoff & Sens. & Spec. & PPV & NPV & Accuracy \\
\hline
\end{tabular}




\begin{tabular}{|l|l|l|l|l|l|}
\hline$>6.2$ & 87.50 & 95.83 & 93.3 & 92.0 & $97.4 \%$ \\
\hline
\end{tabular}

Figure (1): ROC curve of SCD163 before treatment

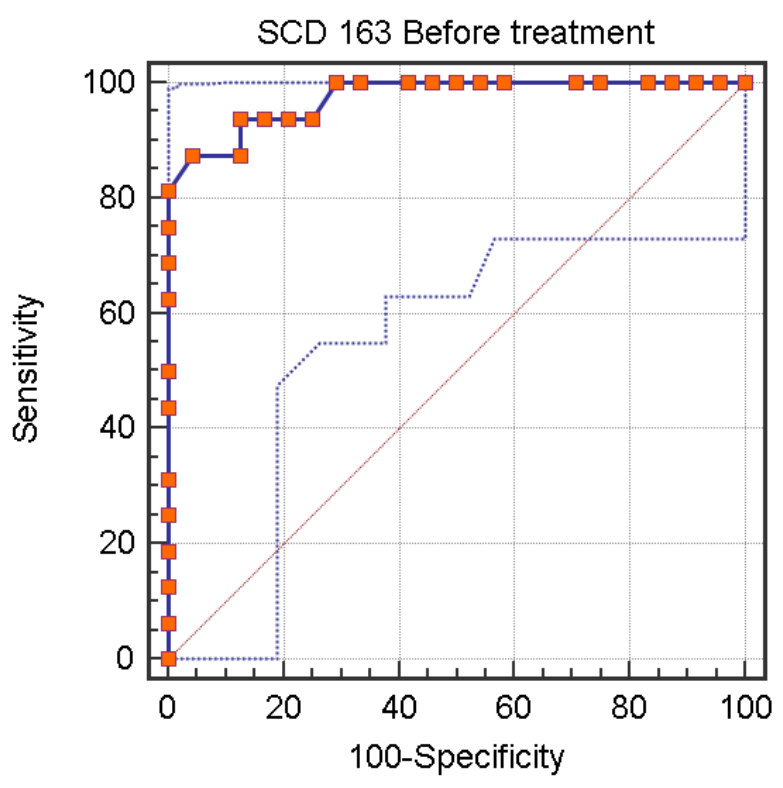

\section{Discussion}

Over 80 million people worldwide are infected with HCV [10]. It promotes inflammation and hence carcinogenesis. Therefore, even in cirrhotic patients, resolving HCV infection should result in lower incidence of HCC [11].

The advent of oral DAAs has changed HCV prognosis, SVR12 has been linked to improved liver function as well as decline in clinical consequences and mortality [12].

And because data about alterations in liver fibrosis following DAAs are few, and follow-up is still limited, the actual effect is based on data from interferon-based studies that suppose that fibrosis regression or resolution occur slowly within years [13], and that regression of cirrhosis is uncertain $[14,15]$. 
CD163 is a hemoglobin scavenger receptor produced by monocytes and macrophages [16]. On cellular activation and inflammation, its soluble form (sCD163) can be identified in serum or plasma [17]. Furthermore, sCD163 is highly expressed by Kupffer cells, suggesting that its serum levels may reflect chronic hepatic inflammation [18].

Soluble CD163 is a well-known marker of portal hypertension and liver disease severity $[19,20]$. Furthermore, in chronic HCV infection, strong relationships between cytotoxic activity, histological inflammation, and fibrosis have been found [21]. Macrophage activity is reduced after chronic HBV antivirals and $\mathrm{HCV}$ interferon treatment, which coincides with reduction in hepatic inflammation [22, 23].

This study aimed to assess the accuracy of soluble CD163 in detecting regression of hepatic fibrosis in $\mathrm{HCV}$ patients treated with DAAs in comparison to standard fibrosis detecting methods.

In this study, chronic HCV infection was more prevalent in males than females, where the total studied subjects comprised 30 males (60\%) and 20 females $(40 \%)$. This was in conformity with the findings of the Egyptian Demographic Health Survey conducted in 2008 and 2015 [24]. This may be attributed to a higher chance of exposure to risk factors for contracting HCV amongst males as compared to females.

Patients' age ranged from 24 to 59 years with the mean of $41.8 \pm 10.146$ and controls age ranged from 21 to 58 years with the mean of $36.6 \pm 12$. This finding is affirmed by the Egyptian demographic health survey conducted in 2008 and 2015 which concluded that chronic HCV prevalence is highest amongst the 45-49 years old age group [24].

The present study showed that complete blood picture parameters were significantly lower in chronic HCV patients than in controls, this is keeping with results of Qamar and Grace [25] who stated that abnormal blood indices in chronic liver disease patients is due to many factors as portal hypertension, alteration of the synthetic bone marrow hormones as granulocyte colony stimulating factor, erythropoietin and thrombopoietin, or bone marrow suppression mediated by toxins.

Our results showed significant higher bilirubin and INR and lower albumin levels among chronic HCV patients when compared to control. These findings are recognized surrogate markers of disease severity reflecting derangements in overall hepatic synthetic function [26]. This in keeping with the results of Sajjadieh and Viunytska [27] who stated that higher bilirubin and prothrombin time in hepatic patients is due to impaired conjugation and excretion as a sign of liver decompensation.

This was also in accordance with Bruno et al. [28] who stated that liver function is compromised due to chronic hepatic inflammation and structural alterations leading to loss of functional liver mass.

In the present study, sCD163 level was higher in chronic HCV patients before treatment $(5.748 \pm 1.854)$ in comparison to control $(1.83 \pm 0.333)$ with $\mathrm{p}$ value $<0.001$, and this goes in conformity with Mascia et al. [29] who stated that even in early stages of HCV-related fibrosis, sCD163 plasma concentrations were greater in HCV patients than in controls, 
implying systemic immune activation and inflammation and proving that sCD163 plays a crucial role in HCV infection pathogenesis [23].

sCD163 levels were also higher in patients with advanced fibrosis (F4) than in early fibrosis patients (F1-F3) with p value <0.001, these results are in accordance with Kazankov et al. [30], and with Andersen et al. [31] who found that sCD163 levels were elevated in patients with HCV-related cirrhosis (F4) compared to those with minimal or no fibrosis (F0-F2) showing that SCD163 may play a role in assessing the severity of hepatitis. However. patients with milder disease still have elevated sCD163, implying macrophage activation even in moderate disease, albeit to a lesser extent [30].

In the current study, sCD163 levels in $\mathrm{HCV}$ patients before treatment ranged from 2.5 to 9.2 $\mathrm{ng} / \mathrm{ml}$ with mean of $5.74 \pm 1.85$ and its level declined significantly 12 weeks after treatment to range from 0.9 to $9.8 \mathrm{ng} / \mathrm{ml}$ with mean of $4.02 \pm 2.81$ although this reduction did not reach control group levels ranging from 1.3 to $2.3 \mathrm{ng} / \mathrm{ml}$ with mean of $1.83 \pm 0.33$, these results are in accordance with Laursen et al. [22] who discovered 32\% reduction in sCD163 levels from 7.4(6.3-8.7) to 5(4.3-5.8) at SVR 12, and stated that the decline was rapid and persisted 12 months after treatment termination which is parallel to the decrease of inflammatory activity and fibrosis.

while following fibrosis using biomarker-based fibrosis methods, APRI and FIB-4 scores didn't show statistically significant improvement 12 weeks after EOT. These results are in contradiction with studies conducted by Knop et al. [32] and Elsharkawy et al. [33] who showed significant improvement of the scores following SVR, and this could be attributed to low sample size of our studied population.

On screening for fibrosis regression with transient elastography (FibroScan $\left.{ }^{\circledR}\right)$ prior to DAAs treatment and 12 weeks after EOT. We found insignificant decline in overall fibroscan measurement (from $17.17 \pm 12.43$ to $16.32 \pm 13.49$ ) Kpa. And this goes in contradiction with what Rout et al. [34] found that there was a significant reduction in fibrosis from baseline value of 5.3-13.8 Kpa to 4.8-11.2 Kpa 12 weeks after EOT with a median decline 0.7 (-0.62.6) Kpa. Other studies had also shown decreasing liver stiffness with DAA therapy $[35,36]$.

This contradiction may be attributed to higher degrees of fibrosis in our studied population or due to short duration of follow up. as a meta-analysis of alterations in liver stiffness after interferon and DAA therapy, showed a mean decline of $2.4 \mathrm{kPa}$ at EOT, $3.1 \mathrm{kPa}$ within the first six months, and $4.1 \mathrm{kPa}$ more than one year later. speculating that the initial decline is due to partial inflammation resolution and that subsequent decline pertains to fibrosis regression, which is supported by much reduction in patients with high baseline inflammation [37].

However. We found that before treatment, ten patients were F1 (25\%), twelve were F2 (30\%), two were F3 (5\%) and sixteen were F4 (40\%). while at SVR12, five patients became F0 (12.5\%), fourteen became F1 (35\%), four became F2 (10\%), two became F3(5\%) and fifteen became F4 (37\%) with P-value 0.046 denoting that overall fibrosis staging improved after the successful HCV eradication, and these results agreed with those of Pan et al. [38] who discovered significant improvement in liver stiffness with at least one stage of fibrosis in $62 \%$ of HCV patients with advanced fibrosis after achieving SVR. 
sCD163 concentration before treatment was found to show a significant positive correlation with total and direct bilirubin, INR, PCR-HCV, AFP, APRI, FIB-4, child score, splenic size, PV diameter and fibroscan, and a significant negative correlation with complete blood picture, albumin and liver size

This correlation with different fibrosis assessment methods like Fibroscan, APRI and FIB-4 scores suggest that $\mathrm{sCD} 163$ is a promising marker of detecting fibrosis and monitoring its regression [39].

While sCD163 correlation with different liver function tests, Child-pugh score, sonographic findings denoting cirrhosis, portal hypertension and decompensation allowing it to be a promising determinant of $\mathrm{HCV}$ related complications [40,41].

Of note, sCD163 did not correlate with ALT suggesting that HCV induced injury is not mediated solely with activated macrophage pathways [42].

Finally, our study demonstrated the diagnostic performance of the best cut-off value of baseline sCD163 in detection of F4 liver cirrhosis as $>6.2 \mathrm{ng} / \mathrm{ml}$ yielded sensitivity of $87.50 \%$, specificity of $95.83 \%, 93.3 \%$ PPV and $92.0 \%$ NPV.

In conclusion sCD163 declines with successful DAA therapy and this is associated with fibrosis regression, confirming the role of macrophages in HCV inflammation and fibrosis and supporting sCD163 promising role in monitoring treatment response in terms of fibrosis regression.

\section{Abbreviations}

HCV: Hepatitis C virus; DAAs: Direct acting antiviral agents; SVR: Sustained virologic response; EOT: End of treatment; APRI: AST to platelets index; FIB-4: Fibrosis-4 score; NPV: Negative predictive value; PPV: Positive predictive value; HCC: Hepatocellular carcinoma.

\section{References}

1- Maasoumy B and Wedemeyer H (2016): Natural history of acute and chronic hepatitis C. Gastroenterology; 26:401-412.

2- Lavanchy D (2011): Evolving epidemiology of hepatitis C virus. Clin. Microbiol. Infect.; 17: 107-115.

3- Poiteau L, Soulier A, Rosa I, et al. (2016): Performance of rapid diagnostic tests for the detection of antibodies to hepatitis $\mathrm{C}$ virus in whole blood collected on dried blood spots. J Viral Hepat; 23: 399-401.

4- Gronbaek H, Sandahl TD, Mortensen C, et al. (2012): Soluble CD163, a marker of Kupffer cell activation, is related to portal hypertension in patients with liver cirrhosis. Aliment Pharmacol Ther; 36: 173-180.

5- Møller HJ (2012): Soluble CD163. Scand J Clin Lab Invest; 72 :1-13. 
6- Laursen T, Brockner C, Kazankov K et al. (2018): Rapid and persistent decline in soluble CD163 with successful direct-acting antiviral therapy and associations with chronic hepatitis C histology. Scandanavian journal of gatroentrology; 53(8): 986-993.

7- El-Akel W, El-Sayed MH, El Kassas M, et al. (2017): National treatment programme of hepatitis C in Egypt: Hepatitis C virus model of care. J Viral Hepat; 24(4): 262-267. doi: 10.1111/jvh.12668.

8- Karić U, Pešić-Pavlović I, Stevanović G, et al. (2018): FIB-4 and APRI scores for predicting severe fibrosis in chronic hepatitis $\mathrm{C}$ - a developing country's perspective in DAA era. J Infect Dev Ctries; 12(3): 178-182. doi:10.3855/jidc.10190.

9- Sterling RK, Lissen E, Clumeck N, et al. (2006): Development of a simple noninvasive index to predict significant fibrosis in patients with $\mathrm{HIV} / \mathrm{HCV}$ coinfection. Hepatol; 43(6): 1317-1325.

10- Razavi H (2016). Making the case for looking beyond WHO estimates for the global burden of hepatitis C and B. J Viral Hepat; 23: 576-584.

11-El Kassas M, Funk AL, Salaheldin M, et al. (2018): Increased recurrence rates of hepatocellular carcinoma after DAA therapy in a hepatitis C-infected Egyptian cohort: A comparative analysis. J Viral Hepat; 25: 623-630.

12- Van der Meer AJ, Berenguer M. (2016): Reversion of disease manifestations after HCV eradication. J Hepatol; 65: 95-108.

13-Shiffman ML, Sterling RK, Contos M, et al. (2014): Long term changes in liver histology following treatment of chronic hepatitis C virus. Ann Hepatol; 13: 340-349.

14-D'Ambrosio R, Aghemo A, Rumi MG, et al. (2012): A morphometric and immunohistochemical study to assess the benefit of a sustained virological response in hepatitis $\mathrm{C}$ virus patients with cirrhosis. Hepatology; 56: 532-543. DOI: 10.1002/hep.25606.

15- Manne V, Akhtar E, Saab S. (2014): Cirrhosis regression in patients with viral hepatitis B and C: a systematic review. J Clin Gastroenterol 2014; 48: e76-e84. DOI: 10.1097/MCG.0000000000000162.

16-Moller HJ, Peterslund NA, Graversen JH et al. (2002): Identification of the hemoglobin scavenger receptor/CD163 as a natural soluble protein in plasma. Blood; 99: 378-380.

17- Hintz KA, Rassias AJ, Wardwell K et al. (2002): Endotoxin induces rapid metalloproteinase-mediated shedding followed by up-regulation of the monocyte hemoglobin scavenger receptor CD163. J Leukoc Biol; 72: 711-717.

18- Mueller JL, Feeney ER, Zheng H, et al. (2015): Circulating soluble CD163 is associated with steatohepatitis and advanced fibrosis in nonalcoholic fatty liver Disease. Clinical and translational gastroenterology; 6: e114. doi:10.1038/ctg.2015.36.

19- Grønbæk H, Rødgaard-Hansen S, Aagaard NK, et al. (2016): CANONIC study investigators of the EASL-CLIF Consortium. Macrophage activation markers predict mortality in patients with liver cirrhosis without or with acute-on chronic liver failure (ACLF). J Hepatol; 64: 813-822. DOI: 10.1016/j.jhep.2015.11.021.

20- Kazankov K, Rode A, Simonsen K, et al. (2016): Macrophage activation marker soluble CD163 may predict disease progression in hepatocellular carcinoma. Scand J Clin Lab Invest; 76: 64-73. DOI: 10.3109/00365513.2015.1099722.

21- Dultz G, Gerber L, Farnik H, et al. (2015): Soluble CD163 is an indicator of liver 
inflammation and fibrosis in patients chronically infected with the hepatitis B virus. J Viral Hepat; 22: 427-432. DOI: 10.1111/jvh.12309.

22- Laursen TL, Wong GL, Kazankov K, et al. (2018): Soluble CD163 and mannose receptor associate with chronic hepatitis $\mathrm{B}$ activity and fibrosis and decline with treatment. J Gastroenterol Hepatol; 33: 484-491. DOI: 10.1111/jgh.13849.

23-Dultz G, Gerber L, Zeuzem S, et al. (2016): The macrophage activation marker CD163 is associated with IL28B genotype and hepatic inflammation in chronic hepatitis C virus infected patients. J Viral Hepat; 23: 267-273. DOI: 10.1111/jvh.12488.

24- Kandeel A, Genedy M, El-Refai S, et al. (2017): The prevalence of hepatitis C virus infection in Egypt 2015: implications for future policy on prevention and treatment. Liver Int; 37: 45-53.

25- Qamar A and grace N (2009): Abnormal hematological indices in cirrhosis. Can j gastroenterol; 23(6):441-445.

26- Bonacini M, Hadi G, Govindarajan S, et al. (1997): Utility of a discriminant score for diagnosing advanced fibrosis or cirrhosis in patients with chronic hepatitis $\mathrm{C}$ virus infection. Am J Gastroenterol; 92:1302-1304.

27-Sajjadieh M, Viunytska L. (2008): prothrombin time in patients with or without fibrotic chronic liver disease, the internet journal of pathology; 8: 1-5.

28- Bruno S, Zuin M, Crosignani A, et al. (2009): Predicting mortality risk in patients with compensated HCV-induced cirrhosis: a long-term prospective study. Am J Gastroenterol; 104: 1147-1158. DOI: 10.1038/ajg.2009.31.

29- Mascia C, Vita S, Zuccala P, et al (2017): Changes in inflammatory biomarkers in HVC-infected patients undergoing direct acting antiviral regimens with or without interferon, PLoS One;12(6). doi: 10.1371/journal.pone.0179400.

30- Kazankov K, Barrera F, Møller HJ, et al. (2014): Soluble CD163, a macrophage activation marker, is independently associated with fibrosis in patients with chronic viral hepatitis B and C. Hepatology; 60(2): 521-530. doi.org/10.1002/hep. 27129.

31- Andersen ES, Rodgaard-Hansen S, Moessner B, et al. (2014): Macrophage-related serum biomarkers soluble CD163 (sCD163) and soluble mannose receptor (sMR) to differentiate mild liver fibrosis from cirrhosis in patients with chronic hepatitis $\mathrm{C}$ : a pilot study. Eur J Clin Microbiol Infect Dis; 33: 117-122.

32-Knop V, Hoppe D, Welzel T, et al. (2016): Regression of fibrosis and portal hypertension in $\mathrm{HCV}$-associated cirrhosis and sustained virologic response after interferon-free antiviral therapy. J Viral Hepat; 23: 994-1002. DOI: 10.1111/jvh.12578.

33-Elsharkawy A, Alem SA, Fouad R, et al. (2017): Changes in liver stiffness measurements and fibrosis scores following sofosbuvir based treatment regimens without interferon. J Gastroenterol Hepatol; 32: 1624-1630. DOI: 10.1111/jgh.13758.

34- Rout G, Nayak B, Patel AH, et al. (2019): Therapy with oral directly acting agents in hepatitis $\mathrm{C}$ infection is associated with reduction in fibrosis and increase in hepatic steatosis on transient elastography. J. Clin. Exp. Hepatol; 9: 207-214. doi: 10.1016/j.jceh.2018.06.009.

35- Kobayashi N, Iijima H, Tada T, et al. (2018): Changes in liver stiffness and steatosis among patients with hepatitis $\mathrm{C}$ virus infection who received direct-acting antiviral therapy and achieved sustained virological response. Eur J Gastroenterol Hepatol; 30: 546-551. DOI: 10.1097/MEG.0000000000001106. 
36- Lens S, Alvarado-Tapias E, Mariño Z, et al. (2017): Effects of all-oral anti-viral therapy on HVPG and systemic hemodynamics in patients with hepatitis $\mathrm{C}$ virusassociated cirrhosis. Gastroenterol; 153: 1273-1283. DOI: 10.1053/j.gastro.2017.07.016

37-Singh S, Facciorusso A, Loomba R, et al. (2018): Magnitude and Kinetics of Decrease in Liver Stiffness After Antiviral Therapy in Patients with Chronic Hepatitis C: A Systematic Review and Meta-analysis. Clin Gastroenterol Hepatol; 16: 27-38. DOI: 10.1016/j.cgh.2017.04.038.

38- Pan JJ, Bao F, Du E, et al. (2018): morphometry confirms fibrosis regression from sustained virological response to direct-Acting antivirals for hepatitis C, Hepatol commun; 2(11): 1320-1330.

39- Kuniholm MH, Hanna DB, Landay AL, et al. (2015): sCD163 is Associated with Non-Invasive Measures of Liver Fibrosis in HCV and HCV/HIV Infected Women. Hepatology; 61(2): 734-735. doi:10.1002/hep.27303.

40- Rode A, Nicoll A, Moller HJ, et al. (2013): Hepatic macrophage activation predicts clinical decompensation in chronic liver disease. Gut; 62: 1231-1232.

41-Holland-Fischer P, Gronbaek H, Sandahl TD, et al. (2011): Kupffer cells are activated in cirrhotic portal hypertension and not normalised by TIPS. Gut; 60: 13891393.

42- Kostadinova L, Shive CL, Zebrowski E, et al. (2018): Soluble markers of immune activation differentially normalize and selectively associate with improvement in AST, ALT, albumin, and transient elastography during IFN-free HCV therapy. Pathog Immun; 3: 149-163. 
